\title{
Pulmonary Artery Stenosis
}

National Cancer Institute

\section{Source}

National Cancer Institute. Pulmonary Artery Stenosis. NCI Thesaurus. Code C99030.

A cong enital or acquired cardiovascular abnormality characterized by the narrowing of the lumen of the main pulmonary artery or its branches. Signs and symptoms include dyspnea, tachypnea, tachycardia, fatigue, and edema. 